\title{
Editorial
}

\section{Heat in discussions surrounding ERA 2018 submissions}

TEXT editors recently conducted an informal email survey with a group of senior creative writing academics around Australia. The survey asked:

What was the main topic of discussion for you and your colleagues in relation to preparations for the ERA 2018 round submissions?

We are aware that the conversations around ERA in each university are different, and we wanted to draw some of those diverse discussions together, at least to identify what the main concerns were.

Here follows a selection of those responses, presented anonymously. Clearly there is some heat in discussion of the issues raised. (It's wonderful to see writers writing angrily.) One respondent wrote: 'I am happy to respond to your call for info on ERA which I consider to be a shambles!'

We can start with the disenfranchised:

Well, at my university I was not involved in any discussions nor am I aware of what our submission was, nor who from the Writing area (if anyone) was involved - it all seems to be very secret. Obviously I'm not happy about this and obviously, again, I would not want this to be made public.

These sentiments were repeated by:

In previous ERA submissions staff in Writing have had discussions in preparation for ERA, but this time we have had no input to the A/Dean Research's submission.

It's all been done by management.

Which was backed up by:

There wasn't a discussion. There was an instruction to provide ERA statements to match a list of publications that had been selected by I know not whom. When I responded to the request asking why they had not made a full capture (of my work, curious if they had made an audit based on perceived quality) they said, basically, sorry, we forgot that book, can you send us a statement for that too. Very amateur in my opinion.

Many of us are familiar with the fact that even when discussions do get going, they involve matters of nuancing, of cat-and-mouse strategies, of wanting to spy on other universities' - and the ARC's - thinking and procedures, of rumour and secrecy.

A more measured response reported discussions about how creative writing was yoked with music and performance in the 1904 category: 
I think one of the key conversation points for us was the thinking through of the relationship between the outputs of the music program staff and those from staff in the writing program(s): how to balance those two quite different kinds of outputs in the $30 \%$ for 1904 , and how to present an overarching narrative that acknowledges that both those disciplines are active and interesting at our institution.

And another, confidentially, talked about the nuancing involved in choosing how to separate Literary Studies and Creative Writing outputs, how to play off Music, Theatre, Writing and Literary Studies for a better ERA result in the long run.

The question of scholarly articles vs creative outputs was a topic of conversation:

Another key issue was trying to think about the point at which critical scholarly articles in both the music and the writing disciplines, written by people who predominantly identify as practitioners, might be read by assessors as contributing more convincingly to either the cultural studies or literary studies disciplines. What is it that tips a piece of traditional scholarly research more towards 1904 as a category?

The question of compiling portfolios does not affect other disciplines, such as Literary Studies. While in one university significant discussion about portfolios for creative outputs 'came pretty much to nothing in terms of what the submission eventually looked like, the whole idea of portfolioing being questioned', other discussions were more positive:

Portfolios were really important for us, mainly because we found it easier to offer a convincing story of the research topic, approach, sustained attention and reach of a bucketful of poems, say, or artworks, rather than of individual minor works. In some cases slender volumes were included in groups of stand-alone poems or stories: in short, whichever NTROs were addressing the same research question ended up together in the same portfolio. (We took this approach for a few reasons, not least that we had way over the minimum 50 outputs so had capacity to make the whole submission as tight and strong as possible; because we thought the works gathered together into their portfolios were clearly treading the same ground, in terms of topic of enquiry; that a bunch of them together were more credible as research (when independently they looked perhaps more like art practice); and we thought it might be easier for reviewers to see what our researchers were trying to do if they read a portfolio of a dozen poems, than if they read a dozen discrete poems.)

Another compiler said:

...yes, I was asked to "meaningfully cluster" individual poems into an ERA suite (my term). This was easy enough for me because they were all conceptually clustered towards certain book publications, but I can imagine this to be a nightmare if you weren't writing [topic excised] ... (which is after all most poets).

And another: 
In selecting NTROs for the $30 \%$ peer review - whether portfolio or major work - we tried, as far as possible, to select those where there was at least one traditional (peer-reviewed) output on the same research topic; and if the trad. work was strong, and in a good outlet, we selected that too for peer review. And overall we took pains to ensure a close fit between all the works selected for peer review, and the story about our FoR19 research we had told in the explanatory statement.

This was reflected by:

Discussion focused around which academic to put forward a portfolio from, and then was largely centred around how to tell a story about the portfolio. This involved putting a narrative to the thematic concerns that tied the portfolio together, to demonstrate how the various parts connected and formed a coherent whole.

Another response targeted the research statement and how it has become part of the politics and manoeuvring in at least one university's ERA process:

...we were asked to remove the ERA statements from the end of creative works that had been published in TEXT. It seems the ERA doesn't like them attached to the publication (or that's what we were told by someone who is supposed to know). Having them at the end of each work also means that stating that the work was peer reviewed and published in a quality journal (a primary indication of significance) reads a bit oddly when that statement appears in the journal in question itself.

TEXT and the research statement were mentioned again in this response:

TEXT's primacy in the field, in the 1904 code specifically, was an issue for us as it appears reviewers are looking for variation. The difficulty for some in writing acceptable research statements for creative works and portfolios was an ongoing discussion point too. In terms of these statements, we often discussed the TEXT published research statements (which [names deleted] pioneered). On one hand, it is so important these statements are good quality, and the TEXT ones usually are - and being available in a published format helps lend legitimacy in the ERA submission. But on the other, these statements are also then "locked" and unable to be edited so, at times, we were "stuck" with something that didn't quite suit our needs. But they certainly were a blessing for us at times.

The issues surrounding 1904 submissions are broad and deep. They involve what happens at personal, campus, and national levels. They involve management practice, community identity and personal feeling. Creative writing academics have indicated that they take the ERA submission process personally: it involves the rating, ranking and valuing of their work. It also involves their employment performance, as reflected here:

I was ... appalled to learn that they had not routinely asked all Writing staff. Who makes this call? I felt absolutely furious about this and very powerless. It is something I hope to do "good work" in in my DGR role i.e. advocate for us as an FOR code cluster. 
And, in conclusion, one of our eminent colleagues had this to say:

I have some very real questions: Why is it the responsibility of an individual university to fund and invite ERA specialists from other universities to in-service staff on the content of their Research Statements? Why does ERA not supply a more relevant, comprehensive and transparent FOLIO OF SUCCESSFUL Research Statements for staff to emulate? Why is it that some universities have each staff member write their own Research Statement while some wealthier universities can afford to employ a Research Statement writer to gather the research from a relevant FOR code and write all the submissions for that code in a uniform manner? (Purportedly some universities allow for the latter - true or false? - who knows? That's the ERA rumour factory at work which should not exist as such rumours are unprofessional and academically divisive). In short: Why do ERA Research Statements remain a "guessing game" in which some universities recommend playing the game "this way" and some universities recommend playing it "that way"?... One final thought: do the Sandstones do better because they can afford to rent "emeritus" writers and/or "writers in residence" whose substantive publications enrich that university's ERA rating? All of these doubts and fears circulate in the ERA rumour factory and should be overtly addressed and crushed. Thanks for this opportunity to vent my feelings.

All together the comments gathered here reflect a sense that there is little clarity or parity in the ERA process for practitioner researchers and that in many universities there is a disconnect between research management and creative academics. We feel that this has been a worthwhile survey. Perhaps someone will take up the challenge to undertake more probing research.

\section{—Nigel Krauth and Dallas Baker}

Scholarly contributions to this issue of TEXT include a broad range of topics from reflective practice, improvisation, and collaborative writing as method, to questions of examination, experimentation, misinterpretation and activism.

In 'On reflection: The role, mode and medium of the reflective component in practice as research', Michael Green and Tony Williams discuss the complexities of the relationship between the exegetical and creative components in Creative Writing (and more generally, Creative Arts) research. The article draws on debate over three decades in the British context where, as happened in Australia over the same period, Creative Arts research was tested by government research bodies and by academics themselves with a view to substantiating its value and identifying its component parts. Green and Williams argue that reflection has become the dominant and indeed default mode of discourse in works accompanying creative practice as research, and that this has happened at the expense of a wider range of modes and media that could work to allow us to know and understand creative practice differently. Theirs is a timely and thought-provoking argument.

In an eloquent article on essaying as method ('Essaying as method: Risky accounts and composing collectives'), David Carlin adds to his growing body of scholarly work on the form of the essay. Here, Carlin's focus is on 
collaborative essaying as an experimental method worthy of the era of the Anthropocene. The article draws on Bruno Latour's concept of the 'risky account' to argue for the process of collective essaying as a particular mode of accounting for the world. Carlin provides examples from his own practices as a member of essaying collectives, and argues for the validity of this approach as a means of gathering and rehearsing new approaches to world-making, and for generating new forms of 'risky account'.

Continuing the focus on collaboration, in their multi-authored article ('Collaborative writing 'betwixt and between' sits jaggedly against traditional regimes of authorship'), Gail Crimmins, Ali Black, Janice Jones, Sarah Loch and Julianne Impiccini illuminate a range of too often unspoken tensions between collaborative work and the academy. The authors' descriptions and discussion of reflections and collaborations in and amongst the group of five authors are often pithy and insightful. Deeply concerned with ethics as it relates to both process and outcome, this essay demonstrates an admirable courageousness of thought. The article's playfulness with theory, method and form, is achieved without sacrificing any focus or coherence.

The thesis as woven artefact is the focus of Nigel Krauth's thought-provoking contribution to this edition ('Exegesis and artefact as a woven work: Problems of examination'). In this well-paced and energetic article, Krauth challenges the notion, stemming back to the requirements of early non-traditional doctorates in Australia, that the exegesis and the creative work ought to be kept separate. He invokes a range of texts that use fragmented structures and strategies which blend scholarly and non-scholarly approaches in collage-mode, and considers these forms against the kinds of guidelines presented to Australian thesis examiners. How, he asks, might examiners best read and interpret woven doctoral works? Alternatively, what happens when they misinterpret them? Drawing on Wolfgang Iser's reader-response theory, Krauth outlines some of the common problems of readership he has encountered in his experience as a supervisor of woven-work-theses, and offers some solutions that respond to the question of how examiners might read and value the particular contributions made possible by woven works.

Indigo Perry returns to TEXT with an article that documents and theorises the performance of vulnerability in her collaborative, improvisational writing with trumpet player, Andrew Darling. 'Performing vulnerability: On performance writing and improvisation' is an original and engrossing reflection on the act of writing 'live' within an act of performance. In its willingness to explore mystery without always trying to solve it, it contributes to knowledge of experimental forms and practices, and perhaps to the range of knowledge able to be analysed; it is commendable for its articulation of an individual creative process which feels thorough, respectful, and self-critical.

In their article on poetry as a form of activism ('Highways, activism and solastalgia: Poetic responses to Roe 8'), Nandi Chinna and Alison Bartlett present an important argument for all those concerned with the poetics of resistance in the Anthropocene. A testimony of poetic practice, their article charters the use of poetry amongst other performance arts in the fight to save the Western Australian Beeliar wetlands from the push of highway development under the WA State government during 2017. The authors take care to locate activist ecopoetry in the tradition of nature writing, from romantics like Wordsworth and Keats through to Thoreau, Snyder and Indigenous and non-Indigenous Australians like Oodgeroo Noonuccal and Judith Wright. Understanding such poetry as a form of solastalgia, they argue, can help us to see its role in the practice of both protest and mourning. 
The impetus for Ffion Murphy's article 'Speaking for the dead: Writing and the Unknown Australian Soldier' is of an autobiographical nature and perhaps it is this that makes it so strangely moving. In particular, the article examines the notion of prosopopoeia through reference to the Archie Weller poem 'Unknown Soldier.' Murphy argues that Weller's poem 'gives a name, voice, history and character' to the 'anti-hero' whose bones lie in the Tomb of the Unknown Australian Soldier at the Australian War Memorial in Canberra. Murphy teases out the political context of the poem, then explores this master trope's potential import, especially its ability to create a 'fiction of the voice from-beyond-the-grave'. The article speculates on the potency of the 'unknown' and the way that texts like tombs assist concealment and revelation, remembering and forgetting, resurrection and erasure. This is an elegant and confident piece of scholarly work on writing about and on behalf of the unknown.

Justine Ettler and Rebecca Johinke ('A new audience for Justine Ettler's The River Ophelia: In conversation with the author') present an unconventional research article in the form of a conversation, reflecting on the reception of Ettler's The River Ophelia two decades after its original release. How did the packaging, marketing and critical reception of this best-selling Australian novel lead to misreadings of both the genre and the author's relation to the text, and how might readers re-appraise the novel's contribution to the field upon its rerelease two decades on? This broad-ranging, deeply intellectual conversation includes questions around the line between pornography and erotica, the tone and intent of postmodernist fiction, and the lived effect of marketing ploys that conflate author and protagonist. It's an interesting and provocative contribution.

\section{- Julienne van Loon and Ross Watkins}

Special Issue 48, Screenplays as Research Artefacts, edited by Dallas Baker and Craig Batty, mostly draws from the pool of invited participants from the 2016 and 2017 'Scriptwriting as Research' Symposia (SaRS) held at University of Southern Queensland in Toowoomba. The issue compiles a selection of screenplays produced as part of their authors' research programs and projects (practice-led, practice-based), which contain (and thus perform/embody) research findings and new knowledge. In recent years, scriptwriting as a research activity has flourished in universities worldwide, illuminating how the act of writing a stage or screen play is a legitimate and enticing form of knowledge production and dissemination. Even so, this special issue is only the fourth in a line of those focussed on scriptwriting as research published internationally, and the first to focus exclusively on writing for the screen. The works included in Screenplays as Research Artefacts present a range of stories, worlds, characters, visual scenarios and dialogue exchanges that function as vessels for theories and ideas. Furthermore, all of the works embrace fiction as an important method to convey their respective critical concerns, which we believe evidences an emerging hallmark of screenwriting (as) research.

\section{-Dallas Baker and Craig Batty}

\section{TEXT}


General Editor: Nigel Krauth. Editors: Julienne van Loon \& Ross Watkins

Special Issues Editor: Dallas John Baker

text@textjournal.com.au 